J. Lake Sci.(湖泊科学) , 2018, 30(4): 925-936

DOI 10. 18307/2018. 0406

(c) 2018 by Journal of Lake Sciences

\title{
不同密度藻屑堆积下沉积物碳氮磷释放特征
}

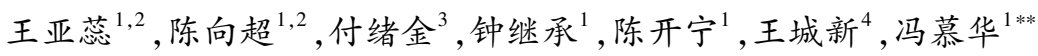 \\ ( 1 : 中国科学院南京地理与湖泊研究所湖泊与环境国家重点实验室,南京 210008) \\ (2: 中国科学院大学,北京 100049) \\ (3: 天津市水利科学研究院,天津 300061 ) \\ (4: 南京工程学院,南京 211167)
}

\begin{abstract}
摘 要: 蓝藻碎屑分解引起氮磷释放已受到广泛关注, 但堆积的藻屑与沉积物交互作用引发污染物释放的效应知之甚 少. 采集于桥水库沉积物柱状样, 设置 5 个藻屑添加组和对照组 (无藻屑添加), 恒温培养 $\left(27 \pm 1^{\circ} \mathrm{C}\right.$ ), 模拟夏季温度条件下 不同密度藻屑堆积下沉积物中碳氮磷释放特征. 结果表明: 藻屑堆积后加强了上覆水中溶解氧与硝态氮的消耗, 5 个藻屑 添加组 18 小时后上覆水均处于厌氧状态. 各实验组上覆水中的溶解性有机碳 (DOC) 浓度在第 3 小时增加, 且 $\mathrm{SUVA}_{254}$ 值 处于 $0.54 \sim 1.74 \mathrm{~L} /(\mathrm{mg} \cdot \mathrm{m})$ 之间, 说明 DOC 可能来源于藻源性释放. 各藻屑添加组培养过程中上覆水的溶解性有机氮 (DON)、铵态氮和正磷酸盐浓度持续增加, 最高平均释放速率分别达 $4.44 、 0.20$ 和 $0.03 \mathrm{mg} /(\mathrm{L} \cdot \mathrm{h})$, 分别为对照组的 $21.73 、 1.76$ 和 67.58 倍; 其中 DON 为溶解性总氮主要存在形态, 在实验结束时 DOC/DON 比值降低, 说明藻屑或者沉积物 有机质短期内并未完全矿化, 且 DOC 优先 DON 被微生物利用. 因此蓝藻碎屑堆积增强了沉积物需氧量, 加快沉积物与水 之间的氮磷营养盐、DOC 循环, 从而对沉积物中污染物地球化学循环过程造成进一步的影响.
\end{abstract}

关键词: 蓝藻水华;沉积物; 营养盐; 溶解性有机碳;于桥水库;藻屑堆积

\section{The releasing characteristics of carbon, nitrogen and phosphorus from sediment under the influence of different densities of algal detritus}

\author{
WANG Yarui ${ }^{1,2}$, CHEN Xiangchao ${ }^{1,2}$, FU Xujin ${ }^{3}$, ZHONG Jicheng ${ }^{1}$, CHEN Kaining ${ }^{1}$, WANG Chengxin ${ }^{4} \&$ \\ FENG Muhua $^{1 \text { ** }}$ \\ (1: State Key Laboratory of Lake Science and Environment, Nanjing Institute of Geography and Limnology, Chinese Academy \\ of Sciences, Nanjing 210008, P.R. China) \\ (2: University of Chinese Academy of Sciences, Beijing 100049, P.R.China) \\ (3: Tianjin Hydraulic Research Institute, Tianjin 300061, P.R. China) \\ (4: Nanjing Institute of Technology, Nanjing 211167, P.R.China)
}

Abstract: The release of nutrients caused by the algae detritus decomposition has been widely studied, however, little is known a-
bout the mechanism of pollutants release induced by the interaction of accumulated algae detritus with sediments. In order to simu-
late the release characteristics of nutrients after different density algal debris settled on sediments on the summer temperature condi-
tion, sediments cores were sampled from Yuqiao Reservoir Watershed and cultured with five density gradients addition treatments
and control without algal detritus under constant temperature condition $\left(27 \pm 1^{\circ} \mathrm{C}\right)$. Results showed that algal detritus enhanced oxy-
gen consumption and nitrate reduction, and overlying water in addition treatments reached anaerobic condition after the incubation
time of 18 hours. The concentration of dissolved organic carbon (DOC) in each addition treatment increased in three hours and the
value of SUVA 254 varied between $0.54-1.74 \mathrm{~L} /(\mathrm{mg} \cdot \mathrm{m})$, suggested that DOC was mainly derived from algal detritus decomposi-
tion. The concentrations of dissolved organic nitrogen $(\mathrm{DON})$, ammonia nitrogen and phosphate in five addition treatments

* 国家自然科学基金项目 (41471075,41171366)、国家水体污染控制与治理科技重大专项 (2017ZX07603-005)、江苏 省高校水处理技术与材料协同创新中心项目和天津市水务局于桥水库专项课题联合资助. 2017-09-20 收稿; 2017-11-01 收修改稿. 王亚芯 (1993 ), 女, 硕士研究生; E-mail: wangyaruilucky@ 126.com.

** 通信作者; E-mail: mhfeng@ niglas.ac.cn. 
increased gradually with the release rates of $4.44 \mathrm{mg} /(\mathrm{L} \cdot \mathrm{h}), 0.20 \mathrm{mg} /(\mathrm{L} \cdot \mathrm{h})$ and $0.025 \mathrm{mg} /(\mathrm{L} \cdot \mathrm{h})$, respectively, and was $21.73,1.76,67.58$ times of the release rates of control, respectively. DON was the main form of dissolved total nitrogen (DTN). Subsequently, the decrease of DOC/DON at the end of incubation suggested that algal detritus and sediments organic matter were not completely mineralized in which DOC took priority over DON being consumed by microorganisms. In general, accumulated algal detritus strengthen benthic oxygen demand and then accelerate the microbial geochemical cycle of nutrients and DOC between the interface of water and sediment.

Keywords: Cyanobacterial bloom; sediments; nutrients; dissolved organic carbon; algae detritus

受温室效应、人类活动等影响, 部分湖泊、河流富营养化日益严重, 蓝藻水华已成为全球瞩目的环境问 题之一 ${ }^{[1]}$. 高密度蓝藻聚集时, 大量蓝藻在湖岸带聚集且不易扩散 ${ }^{[2]}$; 类似重富营养化静水水体区域, 蓝藻 能够堆积数十厘米, 随后腐烂分解释放氮、磷等营养物质 ${ }^{[3-4]}$, 为蓝藻生长繁殖提供营养源 ${ }^{[5-6]}$.

关于蓝藻分解所引起的水质污染效应, 更多的研究侧重于室内模拟高密度蓝藻聚集情况下水质变化特 征 ${ }^{[3-4]}$, 已有大量研究表明高密度蓝藻在衰亡过程能够释放大量营养盐及溶解性有机质 (DOM) 至水体 中 $^{[7-8]}$. 然而高密度蓝藻聚集后易死亡并且形成有机碎屑, 一部分蓝藻碎屑在水体表层被好氧异养微生物利 用 $^{[9-10]}$; 大部分蓝藻碎屑却沉降至沉积物表面, 其分解会导致沉积物碳 $(\mathrm{C})$ 、氮 $(\mathrm{N})$ 、磷 $(\mathrm{P})$ 含量增加 ${ }^{[11]}$. 同 时藻屑有机质作为底栖微生物重要的能量来源, 能够加快微生物代谢进程 ${ }^{[12]}$, 引起沉积物一水界面氮、磷营 养盐通量增加 ${ }^{[13-14]}$, 对沉积物与水中营养盐组成及沉积物微生物群落组成造成一定改变 ${ }^{[15]}$. 另一方面, 沉 积物作为氮、磷等污染负荷的重要 “释放源”, 富含有机氮 $(O N)$ 与有机磷 $(O P)$, 其释放氮、磷污染负荷的途 径主要有两种: (1)沉积物-水界面的新鲜与新生不稳定有机质 (OM) 矿化快速释放; (2)长期埋藏在沉积物中 的有机质矿化缓慢释放 ${ }^{[16]}$. Anna 等 ${ }^{[17]}$ 研究发现沉积物 - 水界面的不稳定 ON、OP 具有更高的分解速率, 释 放的无机氮 (DIN)、尿素和溶解性游离氨基酸贡献了 $27 \% \sim 75 \%$ 藻类 $\mathrm{N}$ 需求量. 藻屑作为沉积物中新生 $\mathrm{OM}$ 易降解, 降解过程中可能会引发沉积物溶氧环境和 $\mathrm{pH}$ 的变化, 沉积物分解释放碳、氮、磷等污染物易受水体 和沉积物基本理化性质的影响, 从而改变沉积物矿化产物及沉积物-水界面营养盐循环. Lomstein 等 $^{\left[{ }^{[1]}\right.}$ 研究 发现在厌氧条件下, 高密度石莼有机碎屑与底泥作用下可增加 $\mathrm{ON}$ 矿化速率, 释放高浓度无机氮至上覆水 中. 因此, 沉积物中内源氮和磷的释放又会成为藻类生长的营养源, 为藻类繁殖和蓝藻水华频繁暴发做出一 定贡献 ${ }^{[19]}$.

针对蓝藻分解所引起的水环境污染效应, 以往文献多以蓝藻由衰到亡过程对沉积物一水界面氮、磷释放 的影响展开研究, 而不同密度蓝藻有机质碎屑堆积与底泥相互作用导致的氮、磷释放鲜有文献报道. 因此本 文针对藻屑堆集现象, 以及此现象可能产生的环境问题展开研究. 本实验参考于桥水库大坝夏季时期蓝藻 常规密度 $\left(10^{8} \mathrm{cells} / \mathrm{L}, \mathrm{Chl}\right.$. a 浓度为 $\left.50 \sim 60 \mu \mathrm{g} / \mathrm{L}\right)$, 在湖心区采集沉积物柱, 设置 6 个藻屑质量添加梯度, 通 过测定上覆水中氮、磷及有机物相关指标, 探索静态条件下随着藻屑堆积密度增加沉积物中碳、氮、磷等营 养物质释放的动态变化趋势, 探讨频繁暴发的水华引起藻屑堆积现象对水生态系统的影响作用.

\section{1 材料与方法}

\section{1 样品采集与处理}

实验水样和泥样均取自于桥水库. 于 2017 年 7 月 8 日在于桥水库湖心区 $\left(40^{\circ} 02^{\prime} 7.29^{\prime \prime} \mathrm{N}, 117^{\circ} 32^{\prime} 36.58^{\prime \prime} \mathrm{E}\right)$, 用装有 $\Phi 86 \mathrm{~mm} \times 500 \mathrm{~mm}$ 有机玻璃管的柱状采泥器采集沉积物柱 18 根, 吸取样柱中的上覆水, 现场测定水 温、溶解氧 ( DO) 和 $\mathrm{pH}$. 剩余水样保存于带有冰盒的保温箱中, 用于水质理化指标分析. 柱子上部缓慢注满 原水并用橡皮塞塞紧, 以免扰动底泥. 采集水库底层水样 $25 \mathrm{~L}$ 在实验室经 $0.45 \mu \mathrm{m}$ 醋酸纤维滤膜过滤后作 为沉积物柱静态培养实验补给水. 所有样品尽快运回实验室置于恒温室 $\left(27 \pm 1^{\circ} \mathrm{C}\right)$, 模拟夏季蓝藻代谢死亡 时的温度, 于暗处静置 $2 \mathrm{~h}$ 使沉积物样稳定. 在大坝区用浮游生物网 (孔径 $64 \mu \mathrm{m}$ ) 采集浓缩藻液 $10 \mathrm{~L}$, 带回 实验室反复冻融 4 5 次以保证藻类死亡 ( 细胞破碎并有藻蓝蛋白及其他内溶物流出), 经蒸馏水反复清洗, 以 5000 转 $/ \mathrm{min}$ 转速离心得到浓缩藻浆, 置于 $-70^{\circ} \mathrm{C}$ 冰箱中保存备用. 使用时用冷冻干燥机冻干, 并研磨过 80 目篮得到干藻屑.

表层沉积物和藻屑的碳、氮、磷含量如表 1 所示. 
表 1 表层沉积物和藻屑理化性质

Tab.1 Physical and chemical properties of surface sediments and algal detritus

\begin{tabular}{ccccc}
\hline & $\mathrm{C} / \%$ & $\mathrm{Chl} . \mathrm{a} /(\mu \mathrm{g} / \mathrm{g})$ & $\mathrm{TN} /(\mathrm{mg} / \mathrm{g})$ & $\mathrm{TP} /(\mathrm{mg} / \mathrm{g})$ \\
\hline 沉积物 & 4.73 & 0.43 & 5.99 & 0.34 \\
藻屑 & 35.41 & 3136.09 & 129.27 & 4.83 \\
\hline
\end{tabular}

\section{2 实验设计}

夏季于桥水库大坝水体 $\mathrm{Chl} . \mathrm{a}$ 平均浓度为 $50 \sim 60 \mu \mathrm{g} / \mathrm{L}^{[20]}$, 为了解夏季现今水华密度下藻首堆积所引起 的污染效应, 设置 $\mathrm{x} 1$ 组 (加人 $0.06 \mathrm{~g}$ 干藻; 约 $6 \mathrm{~g}(\mathrm{dw}) / \mathrm{m}^{2}$; 相当于 Chl. $60 \mu \mathrm{g} / \mathrm{L}$ ). 由于沉降至沉积物表面 处藻屑堆积量可能随时间增多, 因此设置其他 4 个藻屑添加梯度, 具体如表 2 所示. 以不添加藻屑组为对照 组. 每个处理组均设置 3 个平行.

表 2 实验处理组设置

Tab.2 Setting of treatment in the experiment

\begin{tabular}{cccccccc}
\hline & \multicolumn{7}{c}{ 处理组 } \\
\cline { 2 - 7 } & 对照组 & $\mathrm{x} 1$ & $\mathrm{x} 3$ & $\mathrm{x} 5$ & $\mathrm{x} 7$ & $\mathrm{x} 10$ \\
\hline 添加藻屑质量 $/ \mathrm{g}$ & 0 & 0.03 & 0.09 & 0.15 & 0.21 & 0.3 \\
相当于 Chl.a 浓度 $/(\mu \mathrm{g} / \mathrm{L})$ & 0 & 60 & 180 & 300 & 420 & 600 \\
相当于藻屑密度 $/\left(\mathrm{g}(\mathrm{dw}) / \mathrm{m}^{2}\right)$ & 0 & 6 & 18 & 30 & 42 & 60 \\
\hline
\end{tabular}

首先缓慢虹吸柱样中的上覆水, 将冻干的藻屑按上述添加量添加于表层沉积物处, 重新沿管壁缓缓注 人过滤后的水样至上覆水 $30 \mathrm{~cm}$ 处 (沉积物高度均为 $30 \mathrm{~cm}$, 上覆水高度为 $19 \mathrm{~cm}$ ), 此过程中均未扰动沉积 物表面. 实验培养温度与采样时现场温度相同, 为 $27 \pm 1^{\circ} \mathrm{C}$, 避光培养. 开始培养当天记为 0 小时, 按时间序 列分别在第 $0 、 3 、 18 、 42 、 66$ 和 102 小时采样. 用便携式溶氧仪 (HQ40D, 哈希) 测定沉积物-水界面层 DO 和 $\mathrm{pH}$, 采集水-沉积物界面 $0 \sim 1 \mathrm{~cm}$ 处上覆水样 $(100 \mathrm{ml}$ ) 用于水质指标监测, 采完样后沿管壁缓慢补充相同体 积原水至原位置.

\section{3 分析方法}

1.3.1 水体基本理化指标测定 实验期间采用便携式溶氧仪 (HQ40D, 哈希) 测定水体 DO 和 $\mathrm{pH}$.

1.3.2 营养盐指标测定 溶解性总氮 ( DTN)、溶解性有机氮 $(\mathrm{DON})$ 、铵态氮 $\left(\mathrm{NH}_{4}^{+}-\mathrm{N}\right)$ 、硝态氮 $\left(\mathrm{NO}_{3}^{-}-\mathrm{N}\right)$ 、亚硝 态氮 $\left(\mathrm{NO}_{2}^{-}-\mathrm{N}\right)$ 和正磷酸盐 $\left(\mathrm{PO}_{4}^{3-}-\mathrm{P}\right)$ 浓度测定所用液体为过 $0.45 \mu \mathrm{m}$ 醋酸纤维膜的上覆水. 分析方法均参照 《水和废水监测分析方法 (第四版) 》 ${ }^{[21]}$. 其中 DON 为 DTN 与 DIN 浓度 $\left(\mathrm{NH}_{4}^{+}-\mathrm{N} \mathrm{NO}_{3}^{-}-\mathrm{N} 、 \mathrm{NO}_{2}^{-}-\mathrm{N}\right.$ 之和) 之差; 通过称取过 100 目篮孔的 $15 \sim 20 \mathrm{mg}$ 泥样, 用去离子水定溶至 $50 \mathrm{ml}$, 参考水体 TN 和 TP 浓度方法测定沉积 物中 TN 和 TP 含量; Chl.a 浓度采用丙酮提取法测定 ${ }^{[21]}$.

一定时间间隔内营养盐平均释放速率 $(v)$ 采用下式计算:

$$
\begin{gathered}
v_{t_{m} \sim t_{n}}=\left(C_{m}^{\prime}-C_{n}^{\prime}\right) /\left(t_{m}-t_{n}\right) \\
C_{n}^{\prime}=C_{n}+\left(C_{n-1}^{\prime}-C_{0}\right) \cdot \frac{V_{0}}{V}
\end{gathered}
$$

式中, $v_{t_{m}-t_{n}}$ 为 $t_{n} \sim t_{m}$ 时间段内营养盐平均释放速率 $(\mathrm{mg} /(\mathrm{L} \cdot \mathrm{h})) ; C_{m}^{\prime} 、 C_{n}^{\prime}$ 和 $C_{n-1}^{\prime}$ 分别为第 $m 、 n$ 和 $n-1(\geqslant 2)$ 次 校正后的上覆水浓度 $(\mathrm{mg} / \mathrm{L}) ; t_{m}$ 和 $t_{n}$ 分别为第 $m$ 次和第 $n$ 次采样时间点 $(\mathrm{h}) ; C_{n}$ 为第 $n(\geqslant 1)$ 次测定出的 上覆水浓度 $(\mathrm{mg} / \mathrm{L}) ; C_{0}$ 为培养水浓度 $(\mathrm{mg} / \mathrm{L}) ; V$ 和 $V_{0}$ 分别为柱样上覆水体积 $(\mathrm{L})$ 和每次取样体积 $(\mathrm{L})$.

1.3.3 有机物指标测定 紫外一可见光全波扫描 (UV-Vis) : 将经 GF/F 膜 $\left(450^{\circ} \mathrm{C}\right.$ 灼烧 $\left.4 \mathrm{~h}\right)$ 过滤的水样用紫外一 可见分光光度计 (UV2700, 岛津) 扫描测定 DOM 吸收光谱, 扫描范围为 $200 \sim 800 \mathrm{~nm}$, 间隔为 $1 \mathrm{~nm}$; 沉积物 TOC 含量采用元素分析仪 (EA3000) 测定.

$\mathrm{SUVA}_{254}$ : 指在 $254 \mathrm{~nm}$ 波长下紫外吸光系数与溶液中 DOC 浓度 $(\mathrm{mg} / \mathrm{L})$ 的比值, 值越大, 说明有机物分 
子量、有机质的腐殖化水平以及有机物的芳香度越大 ${ }^{[22]}$.

1.3.4 数据处理 数据采用 Excel 2013 软件进行计算, 并用 Origin 9.0 软件绘制数据图; 采用 SPSS 20.0 软件 进行数据相关性分析.

\section{2 结果与分析}

\section{1 藻屑堆积对水体基本理化指标的影响}

由于每个实验柱上覆水来自于同一地点, 所以在第 0 小时 $\mathrm{DO}$ 和 $\mathrm{pH}$ 相同. 各添加组在添加藻屑之后上 覆水 DO 浓度迅速下降 (图 1a), 18 小时后基本处于 $0.1 \mathrm{mg} / \mathrm{L}$ 左右, 并且 5 个添加组 DO 浓度无显著性差异 $(P>0.05)$. 而对照组 DO 浓度由第 0 小时的 $7.56 \mathrm{mg} / \mathrm{L}$ 下降至第 18 小时的 $1.58 \mathrm{mg} / \mathrm{L}$, 降低了 $5.98 \mathrm{mg} / \mathrm{L}$; 之 后除了第 42 小时 DO 浓度低于 $1 \mathrm{mg} / \mathrm{L}$ 外, 其他时间 DO 环境均处于 $1.2 \sim 1.6 \mathrm{mg} / \mathrm{L}$ 的缺氧环境, 与 5 个添加 组形成显著性差异 $(P<0.05)$. 与 DO 变化趋势相同, 各个实验组 $\mathrm{pH}$ 在实验期间不断下降 (图 $1 \mathrm{~b})$, 但均处于 7.67 8.89 之间, 属于弱碱性状态; 且藻屑添加组 $\mathrm{pH}$ 值均低于对照组.

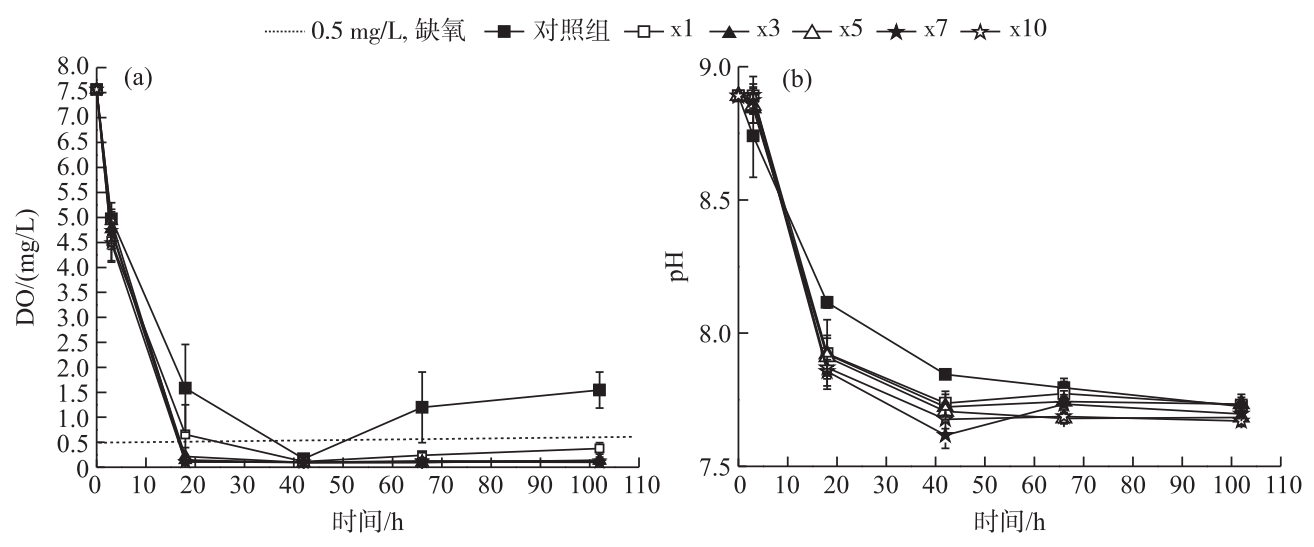

图 1 不同处理组 DO 浓度 $(\mathrm{a})$ 和 $\mathrm{pH}(\mathrm{b})$ 变化

Fig. 1 The variation of dissolved oxygen concentration(a) and $\mathrm{pH}(\mathrm{b})$ in different treatments

\section{2 培养前、后上覆水有机物变化特征}

实验初始 DOC 浓度为 $39.21 \mathrm{mg} / \mathrm{L}$, 各实验组培养后 DOC 浓度均降低(图 2a). 实验开始 $3 \mathrm{~h}$ 后, 对照组 和 $\mathrm{x} 1$ 组 DOC 浓度均高于其他实验组, 分别为 47.40 和 $47.32 \mathrm{mg} / \mathrm{L}$. 实验结束后, 对照组 DOC 浓度降低了 $6.28 \mathrm{mg} / \mathrm{L} ; \mathrm{x} 3 \mathrm{x} 5$ 和 $\mathrm{x} 7$ 组 DOC 浓度变化量均低于对照组; 而 $\mathrm{x} 1$ 和 $\mathrm{x} 10$ 组 DOC 浓度变化最大, 分别降低了 17.02 和 $12.35 \mathrm{mg} / \mathrm{L}$, 为其他藻屑添加组 DOC 浓度减小量的 4 倍或以上. $\mathrm{SUVA}_{254}$ 值与 DOC 浓度变化趋势相 反, 至实验结束, 各实验组 $\mathrm{SUVA}_{254}$ 值均有不同程度增加 (图 2b) ; 其中对照组 $\mathrm{SUVA}_{254}$ 值增加量最低, 为 0.14 $\mathrm{L} /(\mathrm{mg} \cdot \mathrm{m})$; 其他藻屑添加组除 $\mathrm{x} 7$ 组外, $\mathrm{SUVA}_{254}$ 值增加量均高于对照组, 且实验结束时各添加组 $\mathrm{SUVA}_{254}$ 值 均处于 $0.54 \sim 1.74 \mathrm{~L} /(\mathrm{mg} \cdot \mathrm{m})$ 之间.

\section{3 上覆水氮、磷浓度变化特征}

2.3.1 不同形态氮浓度变化 实验起始 DON 浓度为 $4.05 \mathrm{mg} / \mathrm{L}$, 在整个实验过程中各个实验组 DON 浓度随 时间逐渐增加 (图 3a). 实验开始后 $3 \mathrm{~h}$, 各实验组 DON 浓度均增加, 其中 x10 组变化量最高, 为 $13.31 \mathrm{mg} / \mathrm{L}$; 至实验结束, 各实验组 DON 浓度为初始的 6.08 11.20 倍. 各实验组 DON 浓度相比, 实验开始后 $3 \mathrm{~h}$, 对照组 与 $\mathrm{x} 1$ 组 DON 浓度无显著差异, 其他藻屑添加组 (藻密度在 $6 \mathrm{~g}(\mathrm{dw}) / \mathrm{m}^{2}$ 以上) 的 DON 浓度在实验开始后 $3 \mathrm{~h}$ 显著增加, 浓度增加量分别为对照组和 $\mathrm{x} 1$ 组的 8.38 22.19 和 5.03 13.31 倍; 且各实验组 DON 前 $3 \mathrm{~h}$ 平均 释放速率最高, 与藻屑密度呈正比, 其中对照组和 $x 10$ 组分别为 0.13 和 $4.44 \mathrm{mg} /(\mathrm{L} \cdot \mathrm{h})$, 有明显差异.

与 DON 变化趋势相同, 各实验组 $\mathrm{NH}_{4}^{+}-\mathrm{N}$ 浓度随时间增加 (图 3b), 其释放浓度与藻屑密度有关, 且各个 实验组之间具有显著性差异 $(P<0.05)$. 其中 $\mathrm{x} 10$ 组整个实验阶段 $\mathrm{NH}_{4}^{+}-\mathrm{N}$ 平均释放速率最高, 为 $0.06 \mathrm{mg} /$ 

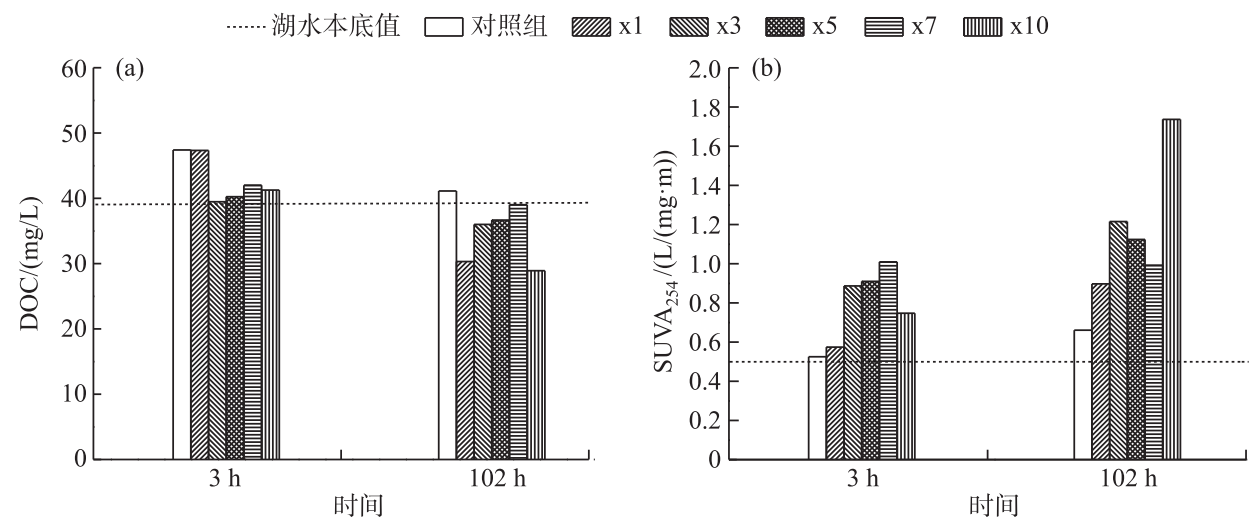

图 2 不同处理组上覆水 DOC 浓度 $(\mathrm{a})$ 和 $\mathrm{SUVA}_{254}$ 值 (b) 随培养时间的变化特征

Fig.2 The variation of DOC concentration(a) and $\mathrm{SUVA}_{254}(\mathrm{~b})$ in different treatments during incubation period

$(\mathrm{L} \cdot \mathrm{h})$, 至实验结束, $\mathrm{NH}_{4}^{+}-\mathrm{N}$ 浓度增加至 $7.32 \mathrm{mg} / \mathrm{L}$, 为初始浓度的 6 倍. 与对照组相比, 藻屑添加组 $\mathrm{NH}_{4}^{+}-\mathrm{N}$ 浓度较高, 培养 18 小时后即超过饮用水源地水质标准 $\left(\mathrm{NH}_{4}^{+}-\mathrm{N} \leqslant 1.0 \mathrm{mg} / \mathrm{L}\right)$, 实验结束时为对照组的 $18.40 \sim$ 62.04 倍.

各实验组 $\mathrm{NO}_{3}^{-}-\mathrm{N}$ 浓度在实验期间逐渐降低 (图 3c), 且对照组 $\mathrm{NO}_{3}^{-}-\mathrm{N}$ 浓度高于藻屑添加组, 浓度维持在 $1.70 \sim 2.72 \mathrm{mg} / \mathrm{L}$ 之间. 而 $\mathrm{x} 7$ 和 $\mathrm{x} 10$ 组 $\mathrm{NO}_{3}^{-}-\mathrm{N}$ 浓度在第 3 小时分别骤降为 0.74 和 $0.65 \mathrm{mg} / \mathrm{L}$, 随后不断降低 并在第 42 小时后维持稳定, 其余藻屑添加组 $\mathrm{NO}_{3}^{-}-\mathrm{N}$ 浓度也逐渐降低, 但均高于 $\mathrm{x} 7$ 和 $\mathrm{x} 10$ 组. $\mathrm{NO}_{2}^{-}-\mathrm{N}$ 浓度均 低于 $0.01 \mathrm{mg} / \mathrm{L}$ (图 3d), 可近似为 $0 \mathrm{mg} / \mathrm{L}$.

2.3.2 上覆水磷浓度变化 短期培养阶段各实验组 $\mathrm{PO}_{4}^{3-}-\mathrm{P}$ 浓度均有所增加 (图 4). 在第 3 小时各藻屑添加 组 $\mathrm{PO}_{4}^{3-}-\mathrm{P}$ 浓度均有所增加, 而第 3 小时和 18 小时各实验组 $\mathrm{PO}_{4}^{3-}-\mathrm{P}$ 浓度无显著变化, 18 102 小时之间 $\mathrm{PO}_{4}^{3-}-\mathrm{P}$ 浓度迅速增加. 藻屑添加组 $\mathrm{PO}_{4}^{3-}-\mathrm{P}$ 浓度均高于对照组, 尤其是藻屑添加量在 $18 \mathrm{~g}(\mathrm{dw}) / \mathrm{m}^{2}(\mathrm{x} 3$ 组) 或 以上的实验组, 实验结束时, $\mathrm{PO}_{4}^{3-}-\mathrm{P}$ 浓度为 $0.54 \sim 0.57 \mathrm{mg} / \mathrm{L}$. 实验前 3 小时, 各藻屑添加组 $\mathrm{PO}_{4}^{3-}-\mathrm{P}$ 平均释放 速率远低于 DON 和 $\mathrm{NH}_{4}^{+}-\mathrm{N}$ 平均释放速率, 处于 $0.002 \sim 0.03 \mathrm{mg} /(\mathrm{L} \cdot \mathrm{h})$ 之间, 且高于整个实验阶段平均释放 速率 $(0.003 \sim 0.006 \mathrm{mg} /(\mathrm{L} \cdot \mathrm{h}))$.

\section{4 藻密度与 DOC 浓度、氮、磷形态浓度之间的关系}

上覆水中各形态氮、无机磷及 DOC 浓度与藻密度的关系如图 5 所示. 在藻屑堆积情况下, 上覆水 DTN、 DON 与 $\mathrm{NH}_{4}^{+}-\mathrm{N}$ 浓度与藻密度呈线性正相关 $(P<0.05)$, 释放量 $(y, \mathrm{mg} / \mathrm{L})$ 与藻屑密度 $\left(x, \mathrm{mg} / \mathrm{m}^{2}\right)$ 分别表现 为: $y=0.28 x+14.30\left(R^{2}=0.93\right) 、 y=0.24 x+9.61\left(R^{2}=0.94\right)$ 和 $y=0.03 x+1.11\left(R^{2}=0.93\right)$. 与之相反, 上覆水中 $\mathrm{NO}_{3}^{-}-\mathrm{N}$ 浓度与藻屑密度呈线性负相关 $\left(R^{2}=0.80, P<0.05\right), \mathrm{DOC} 、 \mathrm{PO}_{4}^{3-}-\mathrm{P}$ 浓度与藻屑密度现为多项式关系: $y=-3.87306 \times 10^{-4} x^{3}+0.036 x^{2}-0.89 x+43.84\left(R^{2}=0.92\right)$ 和 $y=-6.52 \times 10^{-5} x^{2}+0.0065 x+0.058\left(R^{2}=0.97\right)$, 说明在设 置的藻屑密度范围内, 藻屑密度与 $\mathrm{DOC}$ 和 $\mathrm{PO}_{4}^{3-}-\mathrm{P}$ 浓度并非线性相关, 可能是受多方面因素影响的原因.

\section{3 讨论}

氮、磷作为藻类生长繁殖的主要限制性元素, 其流域陆源输人虽然得到一定的控制 ${ }^{[23]}$, 但受多方面的环 境及人为因素影响, 蓝藻水华仍持续发生, 导致藻屑有机质堆积同时使得沉积物富含活性有机质, 成为生物 内源氮、磷蓄积库 ${ }^{[19]}$. 对照组采自于桥水库湖心区, 表层沉积物碳含量为 $4.73 \%$, 静态培养过程中, 由于沉积 物中微生物活动及颗粒态有机质分解消耗氧气, 导致 DO 浓度在 18 小时内急剧降低至 $2 \mathrm{mg} / \mathrm{L}$ 以下, 形成缺 氧环境. 而藻屑属于易降解有机质, 沉降至沉积物中后进一步增加沉积物需氧量 ${ }^{[24]}$. 实验期间添加藻屑组 沉积物一水界面 $1 \mathrm{~cm}$ 处上覆水 DO 快速消耗, 18 小时后 DO 浓度均低于 $0.5 \mathrm{mg} / \mathrm{L}$, 远低于未添加藻屑的对照 组, 造成水体厌氧. García-Robledo 等 ${ }^{[25]}$ 研究微藻碎屑沉降对底栖细菌群落的影响发现, 微藻碎屑沉降后加 

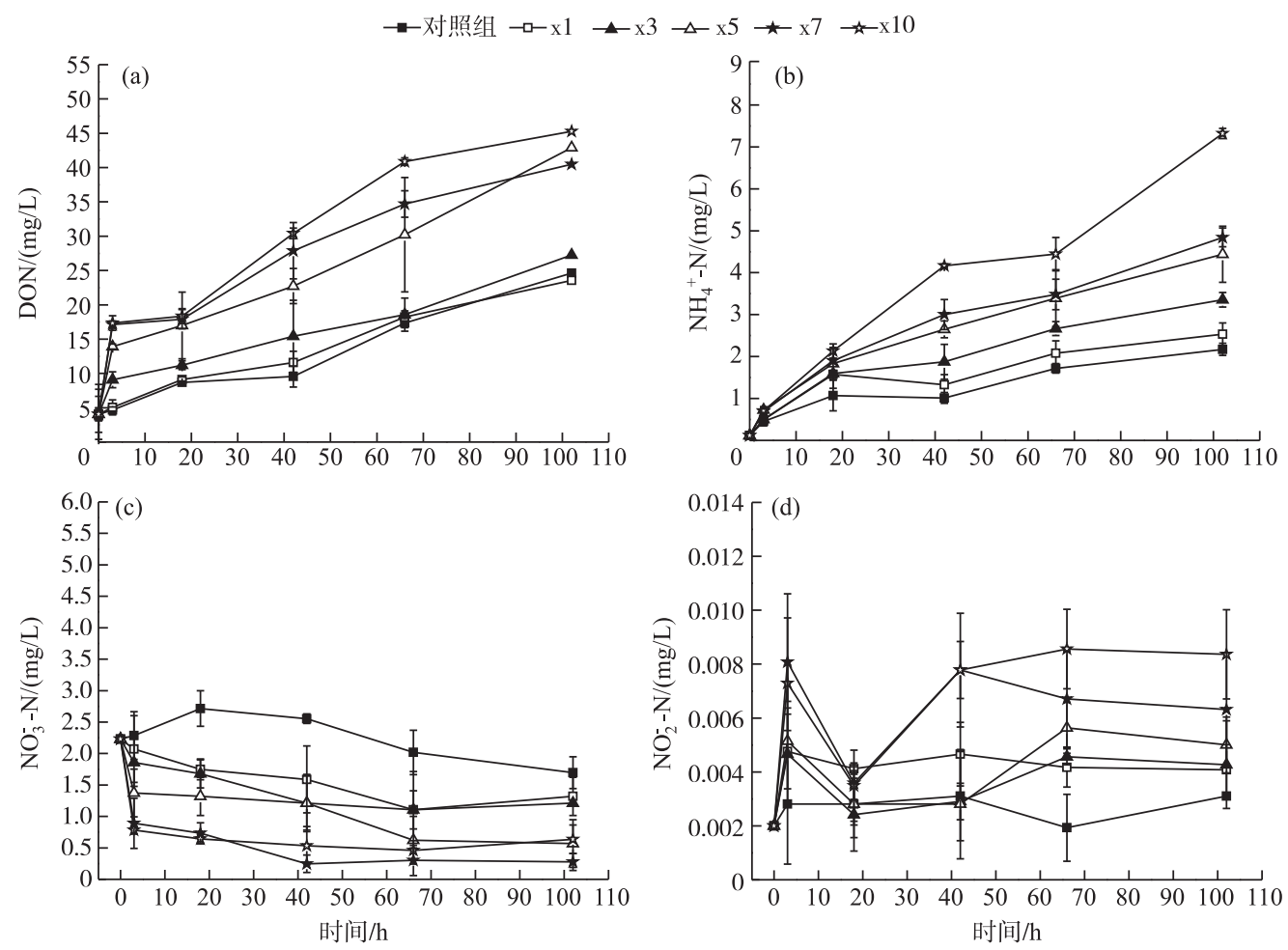

图 3 不同处理组上覆水氮形态浓度随培养时间的变化特征

Fig.3 The variation of different forms of nitrogen in the overlying water of different treatments during incubation period

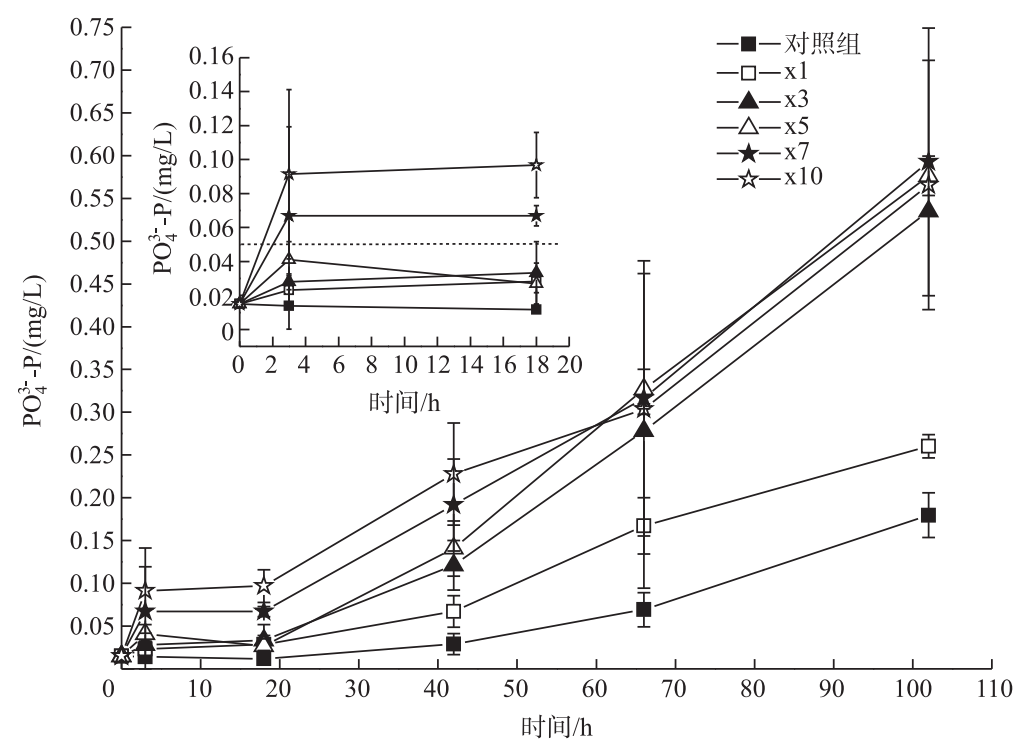

图 4 不同处理组上覆水 $\mathrm{PO}_{4}^{3-}-\mathrm{P}$ 浓度随培养时间的变化特征

Fig.4 The variation of $\mathrm{PO}_{4}^{3-}-\mathrm{P}$ in the overlying water of different treatments during incubation period 

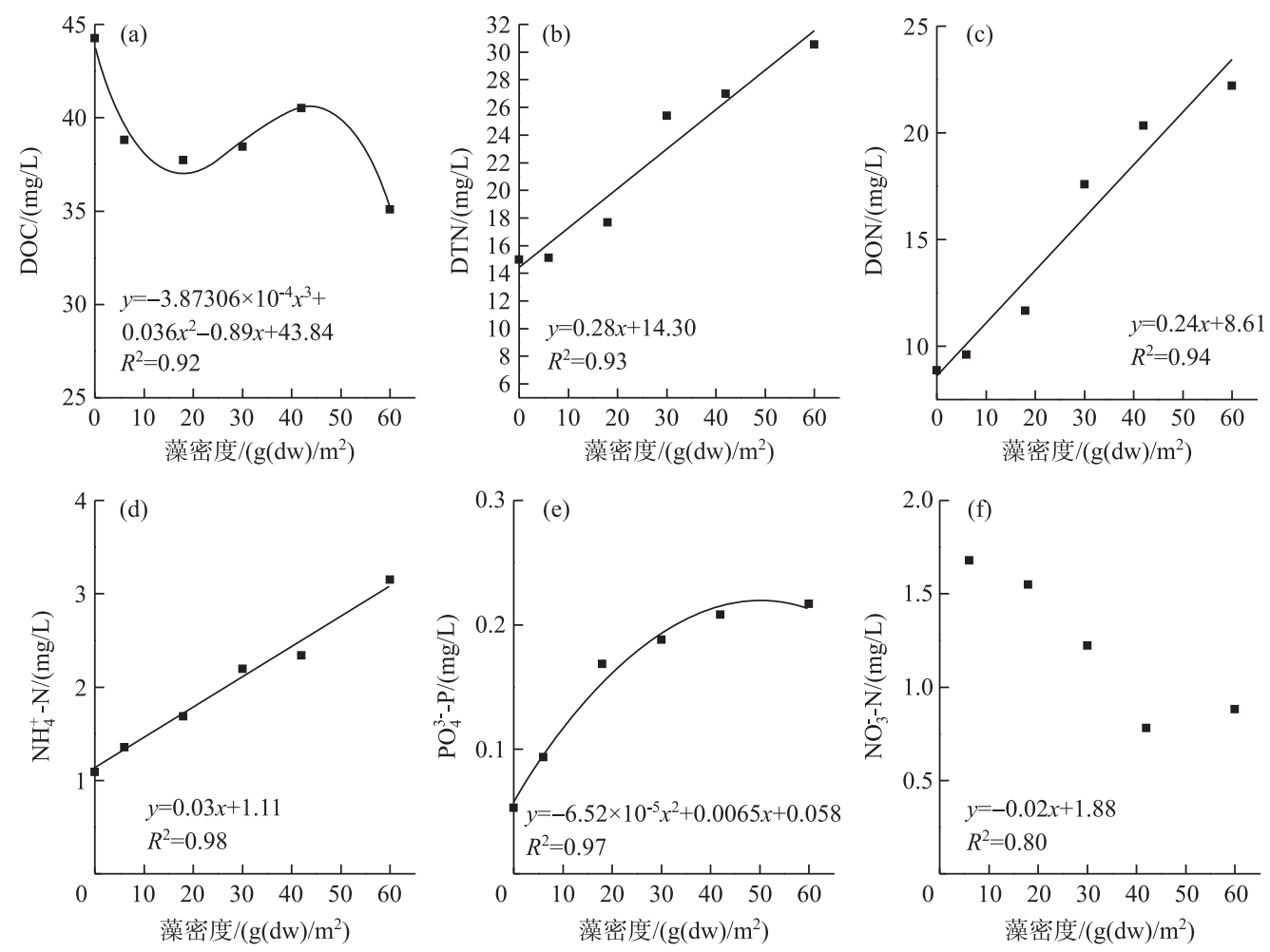

图 5 藻密度与上覆水 $\mathrm{DOC} 、$ 各种形态氮、 $\mathrm{PO}_{4}^{3-}-\mathrm{P}$ 浓度之间的关系

Fig.5 Relationship between the concentrations of DOC, nitrogen, $\mathrm{PO}_{4}^{3-}-\mathrm{P}$ in overlying water and the densities of algal detritus

速细菌群落的快速增长, 并且微生物活性与碳源添加量有关 ${ }^{[26]}$. 随着不同密度藻屑加人为微生物提供新鲜 碳源, 异养微生物活性得到不同程度激发, 加速新陈代谢速度, 消耗水体大量 $\mathrm{DO}^{[25]}$. 造成对照组水体 DO 浓 度与藻屑添加组存在显著性差异 $\left(P_{1}<0.05\right)$ (表 3$)$. 并在分解的过程中产生大量有机酸及二氧化碳 (公式 (3)), 所以随着藻密度增加, 本实验中上覆水 $\mathrm{pH}$ 不断降低 (图 $1 \mathrm{~b}$ ), 且藻屑添加组 $\mathrm{pH}$ 均低于对照组.

$$
11 \mathrm{C}_{6} \mathrm{H}_{12} \mathrm{O}_{6}+24 \mathrm{O}_{2}+8 \mathrm{NH}_{4}^{+}+8 \mathrm{HCO}_{3}^{-} \Leftrightarrow 8 \mathrm{C}_{5} \mathrm{H}_{8} \mathrm{O}_{2} \mathrm{~N}+34 \mathrm{CO}_{2}+54 \mathrm{H}_{2} \mathrm{O}
$$

一般认为植物碎屑降解主要由 3 个过程组成,尽管这些过程有很大部分的重合 ${ }^{[27]}$. 首先碎屑降解初期 是可溶性物质 (与细胞死亡或自溶有关) 的快速释放过程, 且不受微生物活动干扰 ${ }^{[25]}$. 然后, 微生物通过生 物酶分解不稳定生物大分子, 释放出 DOC 和 DON. 最终剩余的大分子物质如纤维素和半纤维素等, 开始极 其缓慢的分解过程 ${ }^{[28]}$. 由于 DOM 中碳生物量超过 50\%, 所以 DOC 常作为间接指标来示踪 DOM 变化 ${ }^{[28]}$. Wickland 等 ${ }^{[28]}$ 研究发现在无菌情况下, 藻类细胞在 3 小时内可释放 $15 \%$ 的细胞有机物 (IOM) 至水体中. 本 实验中在第 3 小时各实验组 DOC 浓度均有不同程度的增加, 可能是由于藻屑细胞内溶物释放导致. Li 等 ${ }^{[29]}$ 研究表明 DOC 浓度影响微生物群落活性及多样性, 微生物细菌密度与 DOC 浓度呈正比, 多样性与 DOC 浓 度呈反比. 实验结束时各处理组 DOC 浓度均降低 (图 2a), 且 DOC/DON 比值有明显降低, DOC/DON 比值处 于 8.01 9.04 之间 (图 6). Lomstein 等 ${ }^{[18]}$ 利用微宇宙装置研究石莼有机碎屑与底泥相互作用后所产生的矿 化产物发现 DOC/DON 比值增加. 本实验结果与之相反, 可能受藻密度影响, 藻密度越大, 微生物细菌较多, DOC 优先 DON 被利用, 导致实验结束时 DOC/DON 比值减小且与藻密度呈反比 ${ }^{[30]}$. 但 DOC 浓度与藻屑密 度并无显著相关性 $(P>0.05)$ (图 5), 可能是由于 DOC 浓度受到诸多因素影响, 如来源、组成、微生物活性和 胶体颗粒物吸附等 ${ }^{[31]}$. SUVA 值作为评估 DOC 化学性质的重要参数, 被广泛应用至水生态系统中 ${ }^{[31]}$. Hong 等 ${ }^{[32]}$ 总结相关文献中藻源性 DOM 的 $\mathrm{SUVA}_{254}$ 值, 发现其值处于 $0.50 \sim 2.30 \mathrm{~L} /(\mathrm{mg} \cdot \mathrm{m})$ 之间, 外源性有机物 
$\mathrm{SUVA}_{254}$ 值高, 处于 $3.20 \sim 4.70 \mathrm{~L} /(\mathrm{mg} \cdot \mathrm{m})$ 之间. 至实验结束各组 $\mathrm{SUVA}_{254}$ 值虽有不同程度的增加, 但均处于 $0.50 \sim 1.80 \mathrm{~L} /(\mathrm{mg} \cdot \mathrm{m})$ 之间, 说明水体中 DOM 部分来源于藻源性有机物.

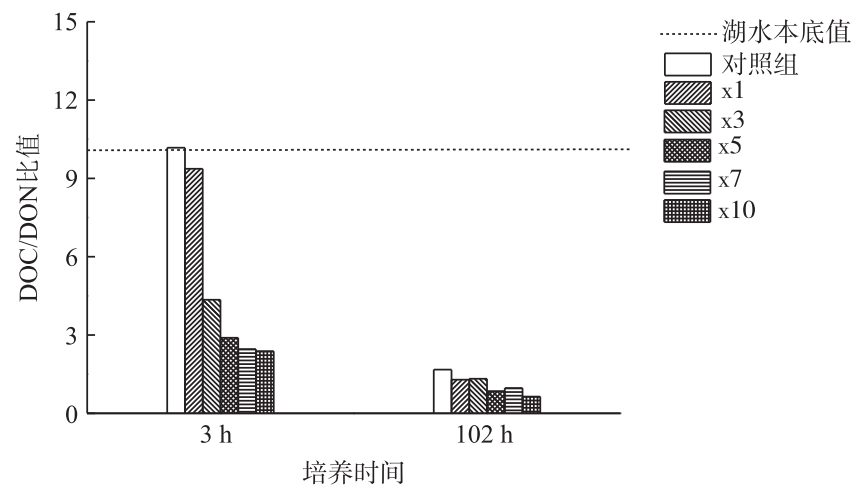

图 6 培养阶段不同处理组上覆水 DOC/DON 比值变化特征

Fig. 6 The variation of DOC/DON in the overlying water of different treatments during incubation period

本实验研究结果表明, 不同密度藻屑堆积情况下, 沉积物中氮、磷释放浓度均有不同程度的增加, 尤其 以 $\mathrm{DON} 、 \mathrm{NH}_{4}^{+}-\mathrm{N}$ 和 $\mathrm{PO}_{4}^{3-}-\mathrm{P}$ 为主 (图 2,3). 上覆水作为污染物释放的汇聚区, 可反映沉积物一水界面污染物释 放过程. 蓝藻碎屑本身是氮、磷的生物内源, 可直接分解释放出氮、磷; 同时其沉降到沉积物表面, 又能通过 矿化作用改变沉积环境的生物理化条件, 从而影响沉积物中氮、磷营养盐释放,两者的贡献量孰轻孰重难以 分辨, 但其结果均增加了上覆水中氮、磷营养盐负荷. 各添加组与对照组 DTN、DON、NH $\mathrm{NH}_{4}^{+}-\mathrm{N}$ 和 $\mathrm{PO}_{4}^{3-}-\mathrm{P}^{3}$ 浓度 进行差异显著性检验 $\left(t\right.$ 检验), $P_{\mathrm{t}}$ 值如表 3 所示. DTN、DON 与 $\mathrm{PO}_{4}^{3-}-\mathrm{P}$ 检验 $P_{\mathrm{t}}$ 值除 $\mathrm{x} 1$ 组外, 均小于 0.05 , 表 现出与对照组的显著性差异, 表明在藻屑密度为 $18 \mathrm{~g}(\mathrm{dw}) / \mathrm{m}^{2}$ 或以上堆积情况下, 沉积物中可短期内释放 DTN、DON 与 $\mathrm{PO}_{4}^{3-}-\mathrm{P}$. 而各添加组 $\mathrm{NH}_{4}^{+}-\mathrm{N}$ 检验的 $P_{\mathrm{t}}$ 值均小于 0.05 , 与对照组形成显著性差异, 表明在藻屑密 度为 $6 \mathrm{~g}(\mathrm{dw}) / \mathrm{m}^{2}$ 或以上堆积情况下, 沉积物中可短期内释放 $\mathrm{NH}_{4}^{+}-\mathrm{N}$ 并引起上覆水浓度出现明显变化. Zhu 等 ${ }^{[2]}$ 对不同湖区藻华由衰到亡模拟实验发现, 藻华衰亡使得部分湖区沉积物营养盐释放浓度增加, 与本实 验结果相符. 整个实验过程对照组 DON 浓度随时间增加, x3、x5、x7 和 x10 组上覆水 DON 浓度在 $3 \mathrm{~h}$ 内快速 增加, 高于对照组与 x1 组; 且各个实验组 DON 占据 DTN 比例超过 $80 \%$, 为 DTN 主要形态, 说明培养期间 DON 一部分可能来源于沉积物有机质 $(\mathrm{SOM})$. 尚丽霞等 ${ }^{[4]}$ 在高密度蓝藻降解实验研究发现在蓝藻分解过 程中释放大量 DTN, 并且 DTN 释放速率与藻密度呈正比. 整个实验阶段, 对照组与 x10 组 DTN 平均释放速 率分别为 0.21 和 $0.45 \mathrm{mg} /(\mathrm{L} \cdot \mathrm{h})$, 而在无沉积物条件下, $\mathrm{x} 10$ 组藻屑密度时 DTN 释放速率为 $0.06 \mathrm{mg} /(\mathrm{L} \cdot \mathrm{h})$ (未发表数据), 可见无沉积物作用下藻屑自身分解释放 DTN 速率远小于同等藻屑量条件下有沉积物的实 验组, 同时也远小于 $x 10$ 组与对照组的差值 $(0.24 \mathrm{mg} /(\mathrm{L} \cdot \mathrm{h}))$. 据此计算, 若不添加沉积物条件下, 实验结束

表 3 藻屑添加组与对照组 $\mathrm{NH}_{4}^{+}-\mathrm{N} 、 \mathrm{DTN} 、 \mathrm{DON} 、 \mathrm{PO}_{4}^{3-}-\mathrm{P} 、 \mathrm{DO}$ 浓度差异显著性检验 $\left(t\right.$ 检验) ${ }^{*}$

Tab.3 $T$ test results of the concentrations of $\mathrm{NH}_{4}^{+}-\mathrm{N}, \mathrm{DTN}, \mathrm{DON}, \mathrm{PO}_{4}^{3-}-\mathrm{P}$ and DO between the algae-addition treatments and the control

\begin{tabular}{cccccc}
\hline 指标 & $\mathrm{x} 1$ & $\mathrm{x} 3$ & $\mathrm{x} 5$ & $\mathrm{x} 7$ & $\mathrm{x} 10$ \\
\hline $\mathrm{NH}_{4}^{+}-\mathrm{N}$ & 0.022 & 0.031 & 0.029 & 0.034 & 0.021 \\
$\mathrm{DTN}$ & 0.688 & 0.020 & 0.012 & 0.009 & 0.013 \\
$\mathrm{DON}$ & 0.333 & 0.023 & 0.009 & 0.007 & 0.010 \\
$\mathrm{PO}_{4}^{3-}-\mathrm{P}$ & 0.057 & 0.040 & 0.034 & 0.047 & 0.034 \\
$\mathrm{DO}$ & 0.010 & 0.036 & 0.040 & 0.035 & 0.017 \\
\hline
\end{tabular}

* 表中数据为 $P_{t}$ 值, $<0.05$ 表示存在显著性差异. 
时藻屑降解所产生的 DTN 释放浓度为 $5.98 \mathrm{mg} / \mathrm{L}$, 远小于本实验中添加沉积物条件下 $\mathrm{x} 10$ 组最终释放的 DTN 浓度 $(53.29 \mathrm{mg} / \mathrm{L})$, 有可能是因为藻屑和沉积物协同作用, 即促进了沉积物矿化, 同时也加速了藻屑降 解, 从而释放了大量 DTN. 但对于沉积物矿化与藻屑分解贡献量无法进行量化, 需进一步研究.

蓝藻碎屑分解释放的不稳定 DON 易被微生物利用继而被分解为小分子有机酸或者 $\mathrm{NH}_{4}^{+}-\mathrm{N}^{[33]} \cdot \mathrm{NH}_{4}^{+}-\mathrm{N}$ 作为 DON 矿化的主要产物 (公式 (4)), 来源主要有以下几个部分: (1沉积物中 DON 矿化产生; (2)藻屑分解 产生的 PON 转化为 DON, DON 被微生物利用转化为 $\mathrm{NH}_{4}^{+}-\mathrm{N}^{[34]}$; 3微生物裂解死亡释放的氨基酸氨化产生 $\mathrm{NH}_{4}^{+}-\mathrm{N}^{[35]}$; (4) 犬氧环境下 $\mathrm{NO}_{3}^{-}-\mathrm{N}$ 通过异化作用还原为 $\mathrm{NH}_{4}^{+}-\mathrm{N}^{[4]}$. 各实验组 $\mathrm{NH}_{4}^{+}-\mathrm{N}$ 浓度随时间增加, $\mathrm{NH}_{4}^{+}-\mathrm{N}$ 在 $18 \mathrm{~h}$ 后成为 $\mathrm{DIN}$ 主要形态氮, 而各个实验组别 $\mathrm{NO}_{3}^{-}-\mathrm{N}$ 浓度逐渐降低. 相关性分析表明, $\mathrm{NH}_{4}^{+}-\mathrm{N}$ 与 $\mathrm{DO}^{-}$ $\mathrm{NO}_{3}^{-}-\mathrm{N} 、 \mathrm{DOC}$ 浓度均呈显著负相关, $\mathrm{NO}_{3}^{-}-\mathrm{N}$ 和 DOC 浓度呈显著正相关 (表 4). $\mathrm{O}_{2}$ 和 $\mathrm{NH}_{4}^{+}-\mathrm{N}$ 是硝化作用正常进 行的必要元素 ${ }^{[36]}$, 藻屑堆积加速了上覆水 $\mathrm{O}_{2}$ 消耗, 硝化作用受到抑制, 可能导致 $\mathrm{NO}_{3}^{-}-\mathrm{N}$ 异化还原为 $\mathrm{NH}_{4}^{+}-\mathrm{N}^{[4]}$, 大量 $\mathrm{NH}_{4}^{+}-\mathrm{N}$ 释放至间隙水中, 从而引起上覆水中 $\mathrm{NH}_{4}^{+}-\mathrm{N}$ 浓度增加, 所以一部分 $\mathrm{NH}_{4}^{+}-\mathrm{N}$ 可能来源于 $\mathrm{NO}_{3}^{-}-\mathrm{N}$ 的异化还原作用. 由于大量藻屑添加, 造成沉积物 $\mathrm{DO}$ 减少或不足, $\mathrm{NO}_{3}^{-}-\mathrm{N}$ 作为电子受体参与藻屑有机质矿 化过程, 且藻屑密度越大, $\mathrm{NO}_{3}^{-}-\mathrm{N}$ 消耗量越大 ( 图 5). García-Robledo 等 ${ }^{[37]}$ 研究发现石莼碎屑加速沉积物中 $\mathrm{O}_{2}$ 消耗与 $\mathrm{NO}_{3}^{-}-\mathrm{N}$ 还原作用, 导致上覆水中 $\mathrm{O}_{2} 、 \mathrm{NO}_{3}^{-}-\mathrm{N}$ 浓度降低, 这与本实验研究结果一致. 至实验结束, 各 个藻屑添加组氨氮浓度增加量处于 $2.41 \sim 7.20 \mathrm{mg} / \mathrm{L}$, 高于对照组氨氮的增加量 $(2.05 \mathrm{mg} / \mathrm{L})$, 所以 $\mathrm{NH}_{4}^{+}-\mathrm{N}$ 的 一部分增量可能来自于沉积物和藻屑降解释放. 因此在藻屑堆积情况下, 沉积物中短期内可释放大量 DON、 $\mathrm{NH}_{4}^{+}-\mathrm{N}$ 至上覆水中, 其中 $\mathrm{NH}_{4}^{+}-\mathrm{N}$ 释放浓度与藻屑密度呈线性正相关 $\left(R^{2}=0.98\right.$ ) ( 图 $5 \mathrm{c}$ ).

$$
\mathrm{R}-\mathrm{CH}\left(\mathrm{NH}_{2}\right)-\mathrm{COOH}+\mathrm{H}_{3} \mathrm{O}^{+} \Leftrightarrow \mathrm{R}-\mathrm{C}(\mathrm{O})-\mathrm{COOH}+\mathrm{NH}_{4}^{+}+\mathrm{H}_{2} \mathrm{O}
$$

作为 $\mathrm{PO}_{4}^{3-}-\mathrm{P}$ 的重要载体, 铁结合态磷 $(\mathrm{Fe}-\mathrm{P})$ 不稳定, 受氧化还原电位控制 ${ }^{[38]}$. Zhang 等 ${ }^{[39]}$ 研究发现蓝 藻碎屑堆积消耗水体 DO, 表明沉积物中氧化还原电位降低, 随后沉积物间隙水中 SRP 与 $\mathrm{Fe}^{2+}$ 浓度升高, 可 能由于 Fe-P 解析所致. 本实验中上覆水 DO 浓度快速降低, 引起沉积物氧化还原电位降低, 与 Zhang 等 ${ }^{[39]}$ 的 研究结果一致. 相关性分析表明, 各个实验组 $\mathrm{PO}_{4}^{3-}-\mathrm{P}$ 浓度与 $\mathrm{DO}$ 浓度均呈显著负相关 (表 4), 说明 $\mathrm{PO}_{4}^{3-}-\mathrm{P}$ 浓度受 DO 浓度影响较大, $\mathrm{PO}_{4}^{3-}-\mathrm{P}$ 有可能一部分来源于铁结合态磷释放 ${ }^{[39]}$, 并且这一作用随蓝藻碎屑量增 大而加强 (图 5e). 各实验组 $\mathrm{PO}_{4}^{3-}-\mathrm{P}$ 浓度与本实验中设置的藻屑添加密度呈正比 $\left(R^{2}=0.97\right.$ ), 并且藻屑添加 组 $\mathrm{PO}_{4}^{3-}-\mathrm{P}$ 浓度高于对照组. 同时无沉积物作用下 $\mathrm{x} 10$ 组藻屑释放 $\mathrm{PO}_{4}^{3-}-\mathrm{P}$ 速率为 $0.003 \mathrm{mg} /(\mathrm{L} \cdot \mathrm{h})($ 未发表数 据), 至实验结束时可释放 $0.31 \mathrm{mg} / \mathrm{L} \mathrm{PO}_{4}^{3-}-\mathrm{P}$, 但低于本实验添加沉积物条件下 $\mathrm{x} 10$ 组实验结束时的 $\mathrm{PO}_{4}^{3-}-\mathrm{P}^{\text {浓 }}$ 度 $(0.57 \mathrm{mg} / \mathrm{L})$, 与 DTN 的结果一致. 有研究表明, 在 DOM 矿化过程中 $\mathrm{P}$ 的释放优先 $\mathrm{C}^{[40]}, \mathrm{PO}_{4}^{3-}-\mathrm{P}$ 作为藻类 水华发生的重要限制因素 ${ }^{[41]}$, 藻屑堆积通过藻屑自身分解或者通过微生物分解、耗氧等生物理化过程改变 引起的 $\mathrm{PO}_{4}^{3-}-\mathrm{P}$ 释放需引起重视.

表 4 上覆水基本理化性质与污染物浓度之间的相关性分析

Tab.4 Correlation between physio-chemical properties of overlying water and the concentration of pollutants

\begin{tabular}{ccccccccc}
\hline 理化指标 & $\mathrm{DO}$ & $\mathrm{pH}$ & $\mathrm{DTN}$ & $\mathrm{PO}_{4}^{3-}-\mathrm{P}$ & $\mathrm{NO}_{3}^{-}-\mathrm{N}$ & $\mathrm{NH}_{4}^{+}-\mathrm{N}$ & $\mathrm{DON}$ & $\mathrm{DOC}$ \\
\hline $\mathrm{DO}$ & 1 & & & & & & & \\
$\mathrm{pH}$ & $0.941^{* *}$ & 1 & & & & & & \\
$\mathrm{DTN}$ & $-0.674^{*}$ & $-0.716^{* *}$ & 1 & & & & \\
$\mathrm{PO}_{4}^{3-}-\mathrm{P}$ & $-0.782^{* *}$ & -0.573 & $0.952^{* *}$ & 1 & & & \\
$\mathrm{NO}_{3}^{-}-\mathrm{N}$ & 0.441 & 0.381 & $-0.783^{* *}$ & $-0.704^{*}$ & 1 & & & \\
$\mathrm{NH}_{4}^{+}-\mathrm{N}$ & $-0.664^{*}$ & $-0.708^{* *}$ & $0.965^{* *}$ & $0.970^{* *}$ & $-0.701^{*}$ & 1 & 1 & \\
$\mathrm{DON}$ & $-0.672^{*}$ & $-0.704^{*}$ & $0.998^{* *}$ & $0.939^{* *}$ & $-0.805^{* *}$ & $0.948^{* *}$ & 1 & 1 \\
$\mathrm{DOC}$ & 0.465 & 0.318 & $0.639^{*}$ & $-0.642^{*}$ & $0.688^{*}$ & $-0.639^{*}$ & $0.629^{*}$ & 1 \\
\hline
\end{tabular}

* 表示在 0.05 水平 $($ 双侧 $)$ 上显著相关; ** 表示在 0.01 水平 (双侧) 上显著相关.

因此, 不同密度藻屑堆积后, 上覆水中 DOC、氮磷营养盐浓度均有不同程度增加. 对照组的污染物释放 
数据表明, 沉积物持续向上覆水释放碳氮磷营养物质; 藻屑添加组 $\mathrm{SUVA}_{254}$ 值表明 DOM (包括 DOC/DON/ DOP) 可能有部分来自于藻屑分解释放, 并且藻屑与沉积物相互作用后上覆水氮、磷浓度高于两者的单独作 用. 但现有数据对于藻屑分解与沉积物矿化贡献量无法量化, 因此下一步将采用同位素示踪方法研究这些 过程对上覆水 DOC 和氮磷浓度增加的贡献, 进一步了解藻屑堆积对沉积物一水界面污染物释放的影响机制.

\section{4 结论}

藻屑堆积情况下可增加沉积物需氧量, 快速消耗底层水 DO 使其浓度下降至 $0.5 \mathrm{mg} / \mathrm{L}$ 以下, 同时伴随 着上覆水中 $\mathrm{pH}$ 不断降低, 使得沉积物一水界面理化环境发生转变. 与此同时, 上覆水 DOC 浓度变化由于受 多方面因素的影响, 实验第 3 小时各藻屑添加组上覆水 DOC 浓度均有不同程度地增加, 紫外-可见吸收光 谱参数 $\mathrm{SUVA}_{254}$ 值表明部分 DOC 来源于藻屑分解作用. 上覆水氮磷浓度受藻屑密度影响较大, 特别是 DON、 $\mathrm{NH}_{4}^{+}-\mathrm{N}$ 和 $\mathrm{PO}_{4}^{3-}-\mathrm{P}$, 增加浓度与藻屑密度呈正比, 最高平均释放速率分别为 4.44、0.20 和 $0.03 \mathrm{mg} /(\mathrm{L} \cdot \mathrm{h})$. 因 此, 藻屑堆积情况下沉积物可成为氮磷的重要 “源”, 驱动蓝藻水华再次暴发, 需对其进行严密监控, 防止其 大范围暴发引发水质危机.

致谢: 本文的研究工作得到了天津市水务局引滦工程于桥水库管理处及天津市水利科学研究院的大力协 助, 金勇在现场采样工作中提供支持和帮助, 在此深表谢意!

\section{5 参考文献}

[ 1 ] Xu HC, Cai HY, Yu GH et al. Insights into extracellular polymeric substances of cyanobacterium Microcystis aeruginosa using fractionation procedure and parallel factor analysis. Water Research, 2013, 47 (6) : 2005-2014. DOI: 10.1016/j. watres.2013.01.019.

[ 2 ] Chen BF, Feng MH, Shang LX et al. Effects on cyanobacterial growth and water quality after harvesting accumulated cyanobacteria in autumn: An in-situ experiment in Lake Chaohu. J Lake Sci, 2016, 28(2) : 253-262. DOI: 10.18307/2016. 0203. [陈丙法, 冯慕华, 尚丽霞等. 秋季聚积蓝藻打捞对蓝藻生长及水质影响的原位实验. 湖泊科学, 2016, 28 (2) : 253-262.]

[ 3 ] Zhu MY, Zhu GW, Zhao LL et al. Influence of algal bloom degradation on nutrient release at the sediment-water interface in Lake Taihu, China. Environmental Science and Pollution Research, 2013, 20(3) : 1803-1811. DOI: 10.1007/s11356012-1084-9.

[ 4 ] Shang LX, Ke F, Li WC et al. Laboratory research on the contaminants release during the anaerobic decomposition of highdensity cyanobacteria. J Lake Sci, 2013, 25(1) : 47-54. DOI: 10.18307/2013.0101. [尚丽霞, 柯凡, 李文朝等. 高密 度蓝藻厌氧分解过程与污染物释放实验研究. 湖泊科学, 2013, 25(1): 47-54.]

[ 5 ] Hansen LS, Blackburn TH. Effect of algal bloom deposition on sediment respiration and fluxes. Marine Biology, 1992,112 (1) : 147-152.

[ 6 ] Yu JL, Li YM, Liu XL et al. The fate of cyanobacterial detritus in the food web of Lake Taihu: A mesocosm study using C13 and N-15 labeling. Hydrobiologia, 2013, 710(1) : 39-46. DOI: 10.1007/s10750-012-1205-y.

[ 7 ] Ask J, Karlsson J, Persson L et al. Whole-lake estimates of carbon flux through algae and bacteria in benthic and pelagic habitats of clear-water lakes. Ecology, 2009, 90(7) : 1923-1932. DOI: 10.1890/07-1855.1.

[ 8 ] Valdemarsen T, Quintana CO, Flindt MR et al. Organic N and P in eutrophic fjord sediments-rates of mineralization and consequences for internal nutrient loading. Biogeosciences, 2015 , 12 (6) : 1765-1779. DOI: 10.5194/bg-12-1765-2015.

[ 9 ] Buchan A, LeCleir GR, Christopher AG et al. Master recyclers: features and functions of bacteria associated with phytoplankton blooms. Nature Reviews Microbiology, 2014, 12(10). DOI: 10.1038/nrmicro3326.

[10] Li K, Guan BH, Liu ZW. Experiments on decomposition rate and release forms of nitrogen and phosphorus from the decomposing cyanobacterial detritus. J Lake Sci, 2011, 23(6) : 919-925. DOI: 10.18307/2011.0614. [李柯, 关保华, 刘 正文. 蓝藻碎屑分解速率及氮磷释放形态的实验分析. 湖泊科学, 2011, 23(6): 919-925.]

[11] Garcia-Robledo E, Corzo A. Effects of macroalgal blooms on carbon and nitrogen biogeochemical cycling in photoautotrophic sediments: an experimental mesocosm. Marine Pollution Bulletin, 2011, 62 ( 7 ) : 1550-1556. DOI: 10. 1016/j. marpolbul.2011.03.044. 
[12] Corzo A, Van Bergeijk SA, Garcia-Robledo E. Effects of green macroalgal blooms on intertidal sediments: net metabolism and carbon and nitrogen contents. Marine Ecology Progress Series, 2009, 380: 81-93. DOI: 10.3354/meps07923.

[13] Henderson RK, Baker A, Parsons SA et al. Characterisation of algogenic organic matter extracted from cyanobacteria, green algae and diatoms. Water Research, 2008, 42(13) : 3435-3445. DOI: 10.1016/j.watres.2007.10.032.

[14] Neubauer ATA, Pedersen AGU, Finster K et al. Benthic decomposition of Zostera marina roots: A controlled laboratory experiment. Journal of Experimental Marine Biology and Ecology, 2004, 313(1) : 105-124. DOI: 10.1016/j.jembe.2004. 08.003 .

[15] Shao KQ, Gao G, Chi KX et al. Decomposition of Microcystis blooms: Implications for the structure of the sediment bacterial community, as assessed by a mesocosm experiment in Lake Taihu, China. Journal of Basic Microbiology, 2013, 53 (6) : 549-554. DOI: 10.1002/jobm.201100532.

[16] Valdemarsen T, Kristensen E, Holmer M. Metabolic threshold and sulfide-buffering in diffusion controlled marine sediments impacted by continuous organic enrichment. Biogeochemistry, 2009, 95(2/3) : 335-353. DOI: 10.1007/s10533009-9340-x.

[17] Tyler AC, McGlathery KJ, Anderson IC. Benthic algae control sediment-water column fluxes of organic and inorganic nitrogen compounds in a temperate lagoon. Limnology and Oceanography, 2003, 48(6) : 2125-2137. DOI: 10.4319/lo.2003. 48.6.2125.

[18] Lomstein B, Guldberg LB, Neubauer Anne-Turi A et al. Benthic decomposition of Ulvalactuca: A controlled laboratory experiment. Aquatic Botany, 2006, 85(4) : 271-281. DOI: 10.1016/j.aquabot.2006.05.006.

[19] Sundbäck K, Miles A, Hulth S et al. Importance of benthic nutrient regeneration during initiation of macroalgal blooms in shallow bays. Marine Ecology Progress Series, 2003, 246: 115-126.

[20] Wang YR, Chen XC, Chen BF et al. The release effect of pollutants in sediment-water interface after algal-debris accumulated on sediments. Acta Scientiae Circumstantiae, 2017, (2) : 1-18. DOI: 10.13671/j.hjkxxb.2017.0279. [王亚莈, 陈 向超, 陈丙法等. 藻屑堆积对沉积物-水界面污染物的释放效应. 环境科学学报, 2017, (2) : 1-18.]

[21] Ministry of Environmental Protection of the People's Republic of China, Editorial Board of Water and Wastewater Monitoring and Analysis Methods eds. Water and Wastewater Monitoring and Analysis Methods: 4th edition. Beijing: China Environmental Science Press, 2002: 243-250, 254-257, 670-671. [国家环境保护总局《水和废水监测分析方法》编委会. 水和废水监测分析方法: 第 4 版. 北京: 中国环境科学出版社, 2002: 243-250, 254-257,670-671.]

[22] Yang LY, Choi JH, Hur J. Benthic flux of dissolved organic matter from lake sediment at different redox conditions and the possible effects of biogeochemical processes. Water Research, 2014, 61: 97-107. DOI: 10.1016/j.watres.2014.05.009.

[23] Zhang X, Zheng JW, Zhou MF et al. Effect of increasing nitrogen/phosphours ratio in loading on the growth on Vallisneria spinulosa. J Lake Sci, 2017, 29(4)：880-886. DOI:10.18307/2017.0411. [张雪, 郑建伟, 周茂飞等. 外源氮磷负荷 比增加对刺苦草 (Vallisneria spinulosa)生长的影响. 湖泊科学, 2017, 29(4): 880-886.]

[24] Morrison JM, Murphy CL, Baker K et al. Microbial communities mediating algal detritus turnover under anaerobic conditions. Peer J, 2017, 5: e2803. DOI: 10.7717/peerj.2803.

[25] Garćia-Robledo E, Corzo A, de Lomas JG et al. Biogeochemical effects of macroalgal decomposition on intertidal microbenthos: A microcosm experiment. Marine Ecology Progress Series, 2008, 356: 139-151. DOI: 10.3354/meps07287.

[26] Reed DC, Rassweiler A, Arkema KK. Biomass rather than growth rate determines variation in net primary production by giant kelp. Ecology, 2008, 89(9) : 2493-2505. DOI: 10.1890/07-1106.1.

[27] Castaldelli G, Welsh DT, Flachi G et al. Decomposition dynamics of the bloom forming macroalga Ulvarigida C. Agardh determined using a 14C-carbon radio-tracer technique. Aquatic Botany, 2003, 75(2) : 111-122. DOI: 10.1016/S03043770 ( 02$) 00167-5$.

[28] Wickland KP, Neff JC, Aiken GR. Dissolved organic carbon in Alaskan boreal forest: Sources, chemical characteristics, and biodegradability. Ecosystems, 2007, 10(8) : 1323-1340. DOI: 10.1007/s10021-007-9101-4.

[29] Li D, Sharp JO, Saikaly PE et al. Dissolved organic carbon influences microbial community composition and diversity in managed aquifer recharge systems. Applied and Environmental Microbiology, 2012, 78(19) : 6819-6828. DOI: 10.1128/ AEM.01223-12.

[30] Gobler CJ, Sanudo-Wilhelmy SA. Cycling of colloidal organic carbon and nitrogen during an estuarine phytoplankton bloom. Limnology and Oceanography, 2003, 48(6) : 2314-2320. DOI: 10.4319/lo.2003.48.6.2314. 
[31] Weishaar JL, Aiken GR, Bergamaschi BA et al. Evaluation of specific ultraviolet absorbance as an indicator of the chemical composition and reactivity of dissolved organic carbon. Environmental Science \& Technology, 2003, 37 (20) : 47024708. DOI: 10.1021/es030360x.

[32] Hong HC, Mazumder A, Wong MH et al. Yield of trihalomethanes and haloacetic acids upon chlorinating algal cells, and its prediction via algal cellular biochemical composition. Water Research, 2008, 42(20) : 4941-4948. DOI: 10.1016/j. watres.2008.09.019.

[33] Barber A, Lalonde K, Mucci A et al. The role of iron in the diagenesis of organic carbon and nitrogen in sediments: A long-term incubation experiment. Marine Chemistry, 2014, 162 : 1-9. DOI: 10.1016/j.marchem.2014.02.007.

[34] Mulholland MR, Gobler CJ, Lee C. Peptide hydrolysis, amino acid oxidation, and nitrogen uptake in communities seasonally dominated by Aureococcus anophagefferens. Limnology and Oceanography, 2002, 47(4) : 1094-1108. DOI: 10.4319/ lo.2002.47.4.1094.

[35] Feng MH, Ngwenya BT, Wang L et al. Bacterial dissolution of fluorapatite as a possible source of elevated dissolved phosphate in the environment. Geochimicaet Cosmochimica Acta, 2011, 75(19) : 5785-5796. DOI: 10. 1016/j. gca. 2011. 07.019.

[36] Rysgaard S, Risgaard-Petersen N, Peter S et al. Oxygen regulation of nitrification and denitrification in sediments. Limnology and Oceanography, 1994, 39(7) : 1643-1652. DOI: 10.4319/lo.1994.39.7.1643.

[37] García-Robledo E, Revsbech NP, Risgaard-Petersen N et al. Changes in N cycling induced by Ulva detritus enrichment of sediments. Aquatic Microbial Ecology, 2013, 69(2) : 113-122. DOI: 10.3354/ame01626.

[38 ] Chen M, Ye TR, Krumholz LR et al. Temperature and cyanobacterial bloom biomass influence phosphorous cycling in eutrophic lake sediments. PLoS One, 2014, 9(3) : e93130. DOI: 10.1371/journal.pone.0093130.

[39] Zhang L, Liao QJH, Gu XZ et al. Oxygen and phosphorus dynamics in freshwater sediment after the deposition of flocculated cyanobacteria and the role of tubificid worms. Journal of Hazardous Materials, 2014, 266: 1-9. DOI: 10.1016/j.jhazmat.2013.12.008.

[40] Aminot A, Kérouel R. Dissolved organic carbon, nitrogen and phosphorus in the NE Atlantic and the NW Mediterranean with particular reference to non-refractory fractions and degradation. Deep Sea Research Part I: Oceanographic Research Papers, 2004, 51(12) : 1975-1999. DOI: 10.1016/j.dsr.2004.07.016.

[41] Mort HP, Slomp CP, Gustafsson BG et al. Phosphorus recycling and burial in Baltic Sea sediments with contrasting redox conditions. Geochimicaet Cosmochimica Acta, 2010, 74(4) : 1350-1362. DOI: 10.1016/j.gca.2009.11.016. 